\title{
Tooth implant supported prosthesis versus implant supported prosthesis- A review of literature and our experience
}

\author{
B. K. Biswas ${ }^{1, *}$, B. Das ${ }^{2}$, A. Saha ${ }^{3}$, Rahul Paul ${ }^{4}$ \\ ${ }^{1} \mathrm{CEO},{ }^{1-4}$ avinash institute of craniofacial and reconstructive surgery, Kolkata, West Bengal India
}

*Corresponding Author: B. K. Biswas

Email: doc135798@yahoo.co.in

\begin{abstract}
Connection of a tooth to an implant by means of prosthesis has always been debatable. The aim of this review is to summarize and discuss the available information and our experience regarding the connection between tooth and implant in fixed partial denture. Thirty four articles related to survival of implant supported prosthesis (ISP) and tooth implant supported prosthesis (TISP), prosthetic options like rigid connector (RC) or non rigid connector (NRC) and complications such as intrusion of teeth were selected and analysed in order to get some outcome. In addition to this, we addressed some of the issues such as advantages, disadvantages, potential risks while fabricating teeth implant supported prosthesis and also drew few recommendations to gain and facilitate enhanced success rate with teeth implant supported prosthesis.
\end{abstract}

Keyword: Tooth implant, Implant supported prosthesis.

\section{Introduction}

Implant supported prostheses are gaining popularity day by day amongst the clinicians due to its long term success rate for the treatment of both partial and completely edentulous patients. However, the acceptance of toothimplant supported prosthetic restoration still remains inconclusive due to lack of proper evidence based literatures.

Implant-tooth supported fixed prostheses are not only preferred by the implantologists, rather it becomes a necessity in some clinical conditions where curtailment of cost factor and reduction of the use of cantilever are high priorities. Findings of some studies are accordant with the fact that implant-tooth connection is beneficial and the success rate is satisfactory. ${ }^{1-3}$ Some clinicians are still in dilemma of splinting tooth and implant due to some potential complications like intrusion of teeth, more stress on teeth, bone loss around implants and increased chances of fracture of either tooth or implant. ${ }^{4}$

Therefore, this article aims to assess and evaluate the data of various studies which have been interpreted that teeth should not be joined with implant and analyse the literature to determine if evidence based decisions could be made concerning the utility of connecting teeth to dental implants.

\section{Material and Methods}

The literature published and articles related to teeth implant supported prosthesis and implant supported prosthesis identified from hand and electronic searches (PubMed, Google Scholar) clinical, laboratory, biomechanical, computer generated and review studies were included.

\section{Review of Literature}

A literature review related to survival rate of TISP and ISP are shown in a tabular format (Table 1) mentioning the number of cases, duration of study, survival rate of implant and bone loss around implants between TISP and ISP for better understanding.

Table 1: Review of Literature

\begin{tabular}{|l|c|c|l|}
\hline \multicolumn{1}{|c|}{ Authors } & \multicolumn{3}{|c|}{ Observations } \\
\cline { 2 - 4 } & Number of cases & Durationof study & \multicolumn{1}{c|}{ Conclusion } \\
\hline Fugazzotto et $\mathrm{al}^{5}$ & 1206 & 3 year to 14 years & $\begin{array}{l}\text { Survival rate 100\%, TISP functioned well without } \\
\text { complication }\end{array}$ \\
\hline Lindh et al $^{6}$ & 127 & Up to 3 years & $\begin{array}{l}\text { TISP as predictable as ISP for bone level and } \\
\text { implant survival (95.4\%) }\end{array}$ \\
\hline Naert et al $^{7}$ & 123 & Up to 15 years & Survival rate ISP (98.4\%), TISP (94.9\%) \\
\hline Niekenig et al $^{8}$ & 84 & 2.2 years to 3.3 years & TISP(97.7\%) as similar to ISP \\
\hline Quirynen et al $^{9}$ & 58 & Up to 6 years & $\begin{array}{l}\text { TISP Survival rate not reported } \\
\text { Less than 2.5\% of ISP failed,limited bone loss } \\
\text { around implants }\end{array}$ \\
\hline Block et al & & 5 years & $\begin{array}{l}\text { Survival rate 90\%, six abutments were lost. Rigid is } \\
\text { better than non-rigid, No difference in bone loss } \\
\text { around implants }\end{array}$ \\
\hline
\end{tabular}




\begin{tabular}{|l|c|c|l|}
\hline${\text { Akca et } \mathrm{al}^{11}}^{11}$ & 34 & 2 years & $\begin{array}{l}\text { Survival rate of TISP 100\%, Bone level remained } \\
\text { stable }\end{array}$ \\
\hline Bragger et al $^{12}$ & 22 & 10 years & Survival rate (93.9\%), TISP (68.2\%) \\
\hline Fartash et al $^{13}$ & 27 & 7 to 13 years & $\begin{array}{l}\text { Unclear result between TISP and ISP. No } \\
\text { difference in bone loss around implants and implant } \\
\text { connected to teeth. }\end{array}$ \\
\hline Kindberg et al $^{14}$ & 41 & 14 months to 9 years & TISP $(92.85 \%)$ and ISP both provided good results \\
\hline Romeo et al & 13 years & $\begin{array}{l}\text { No statistically significant difference between TISP } \\
(90.6 \%) \text { and ISP was Found. }\end{array}$ \\
\hline
\end{tabular}

\section{Discussion}

The combined use of teeth and implants as abutments to support a fixed prosthesis has been recommended for many years, yet only limited data are available on the long-term survival rate of this treatment modality.

\section{Advantages of teeth implant supported prosthesis}

Tooth-implant supported fixed prosthesis can be helpful in restoring functions, anatomy, phonetics, and aesthetics after oral ablative tumour surgery and bone resection in young and adult patients which is documented in previously published case reports. ${ }^{16}$ Connecting teeth and implants was also used to support distraction osteogenesis devices to allow successful augmentationof bone length and height. ${ }^{17}$

Therefore, connecting teeth and implants allowed bridging large bony defects without the need for bone augmentation mesially or distally of a tooth, and this minimizes surgical risks, treatment time, and treatment costs.

The advantages of teeth implant supported prosthesis have been listed below:

1. Cost curtailment of the treatment by reducing number of implants.

2. Desire to splint a mobile key tooth to implant by preserving maximum natural tooth.

3. Widened treatment possibilities

4. Proprioception provided by tooth

5. Reduction for the need of cantilever

6. Preservation of papilla adjacent to the teeth

7. Increased patients acceptance

Disadvantages of tooth implant supported prosthesis

1. Intrusion of tooth

2. Cement bond breakdown

3. Implant or tooth fracture

4. Screw loosening of implant abutment

5. Fracture of prosthesis.

6. Peri-implantitis.

7. Caries, periodontal and endodontic problem.

8. Oral health maintenance is difficult.

\section{Potential problems related with tooth implant supported prosthesis}

There is difference in the tooth implant supporting mechanism when forces are applied. Studies show that apical and lateral movement of teeth about 3-5 um apically and 10-50 um laterally. This dissimilarity in movement can generate greater stress on implants. ${ }^{18}$ The implants are ankylosed and prevent tooth loading; therefore, teeth might contribute little support in this situation and become infraerupted or affected by tooth intrusion.

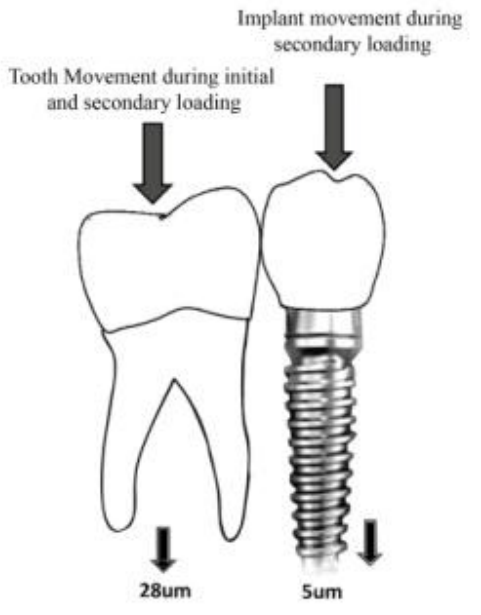

Difference in survival rate of tooth and implant can be another potential cause. Example, tooth might decay or need endodontic restoration over the period of time, which can lead to failure of the whole system.

Though many theories were proposed to explain tooth intrusion, but the exact cause of tooth intrusion remain In distinct.

Tooth intrusion is a multifactorial condition and might be due to

1. Disuse Atrophy ${ }^{19}$

2. Mechanical Binding, ${ }^{20}$

3. Mandibular Flexion And Torsion, ${ }^{21,22}$

4. Flexion Of The Fixed Partial Denture, ${ }^{22,23}$

5. Impaired Rebound Memory ${ }^{19}$

6. Significant Energy Dissipation By The Elastic And Inelastic Deformation Of $\mathrm{PDL}^{19}$

7. Impaction Of Debris And Para functional Activity ${ }^{22}$

\section{Tooth Intrusion}

After splinting the teeth to implants, tooth intrusion is a one-time event, without progression over time. ${ }^{23}$ It takes place within the first year but not within the first 3 months. ${ }^{23}$ The literature demonstrated high discrepancy in the occurrence of intrusion that ranged from $3 \%$ to 
$37 \% .{ }^{24}$ Variable study designs, small sample sizes, using different connectors, and different implant designs may be the cause of this difference. However, the rate of 3.5-5\% seems the most reported figure in many studies. ${ }^{25-27}$

Without the provision of scientific evidence or well controlled studies, some suggestions were introduced via the literature in order to overcome the problem of differential support at both ends of the system. These include bone flexibility, compensatory micro motion within the implant system, introduction of IMZ implants, using permanent cement, using mechanical locking device (screw attachment), or using non-rigid connection between teeth and implants. ${ }^{28}$

\section{Rigid versus Non-rigid connector}

There is a difference of opinion regarding mechanism of connection between tooth and implants. A group of researchers substantiate the rigid connection between implant and tooth as an acceptable procedure due to its reduced rate of mechanical failure. On the contrary, some authors advocated the use of stress breakers between tooth and implant. The rationale behind this expert opinion is dissimilar movement of tooth and implant under occlusal load, where rigid connection between these two may cause additional strain on the implant leading to prosthetic failure of the restoration. ${ }^{29}$ The contradiction arises about the use of in tramobile element (IME) which provides vertical and rotational flexibility in a toothimplant supported prosthesis. ${ }^{30}$ Some researchers claim that IME allows sufficient flexibility to the tooth-implant supported prosthesis compensating dissimilar movement pattern between natural tooth and implant, whereas another group of authors are opposed this opinion. ${ }^{31}$ According to McGlumpy et al. ${ }^{32}$ even load distribution is ensured by the bending of the titanium superstructure screw that provides the required flexibility. Amongst different types of non-rigid connectors, key and keyway are the most common and popular because the placement of the keyway on the natural teeth seems to be beneficial as it would permit physiological tooth movement under functional occlusal load. Though most clinical observations find no significant differences in function between rigid and non-rigid connections in TISP, yet some studies evaluating bone loss around implants using long term radiographic follow-up indicate more bone loss with rigid connection compared to non-rigid connection. ${ }^{33}$ Some authors recommended rigid connection because the prosthesis and implant possess an internal flexibility to compensate the mismatch in movement pattern between the implant and tooth whereas several non-rigid connectors have also been proposed by some researchers in this respect. $^{34}$

\section{Recommendations for Tooth Implant Supported Prosthesis}

Appropriate diagnosis, case selection and execution of proper treatment plan are paramount to address the biomechanical challenges associated with connection of implant to natural teeth.
1. Selection of healthy teeth-periodontally stable/nonstable (adequate root length) having dense bone.

2. Rigid connection of the tooth and implant (no stress breakers), employing large solder joints to enhance rigidity, or use one-piece castings.

3. One side implant with one side natural tooth (telescopic crown)

4. Providing retention form with minimal taper of axial walls on abutment teeth. Enhancing the resistance form with boxes and retention grooves if the clinical crown is not sufficiently long.

5. Maintaining parallelism of the implant abutment to the preparation of the tooth.

6. Using permanent cementation (no screw retention or temporary cementation).

7. Use of short bridge span. Preferably, one pontic between two abutments. However, with additional tooth or implant support or cross-arch stabilization, additional pontics may be used.

8. Occlusal forces should be meticulously directed to the opposing arch.

9. In general, use of TISPs is preferably avoided in patients with para functional habits, such as bruxism.

10. Cantilever extensions should be used cautiously; however, they may be incorporated when tooth or implant support is adequate, eg, cantilever-implantimplant-pontic- tooth-tooth.

11. TISPs in patients with uncontrolled caries should be avoided; ISPs are preferred.

12. Pulpless teeth with extensive missing coronal tooth structure or root canal anatomy that is inadequate to predictably retain a core or post and core should not be used in a TISP.

\section{Conclusion}

No conclusive studies are available to show the best number of implants and teeth to be connected using this treatment option. In addition, no conclusive evidence is available to show the best prosthesis span length that can be supported via connecting teeth and implants, but maximum number of implant can provide initial (primary) stability with long term success. Likewise maximum number of natural teeth also provide initial support to the implant where initial load and stress can be shared to the natural teeth, which ultimately helps in implant survival and immediate loading. Studies on patient and clinician satisfaction with this treatment paradigm are not available. In order to improve treatment success rate, it is better to avoid using short implants, poor bone quality, and endodontically treated teeth when this treatment paradigm is considered. In our study where using rigid connection and permanent cementation shows less tooth intrusion and less complications related to long term follow up. A risk benefit analysis and anticipated complications should always be explained to the patient prior to opting for TISP.

Based on a limited number of studies, it can be concluded that connecting teeth to implants is a viable treatment option in properly selected patients. We also 
believe that it is essential to evaluate the patient not only with a surgical perspective, but also from a prosthodontic point of view. Country like India where cost is an important determinant factor for selecting treatment modality where implant is still costly for the common people. Therefore, further research is still required on many aspects of this treatment paradigm.

\section{Our experience}

Chief author had very vast experience regarding tooth implant supported prosthesis at Avinash Dental Laboratories \& Research Institute Private Ltd. He has been doing implants since 1996 till date, and placed more than five thousands implants followed by prosthesis.

\section{A few cases of teeth implant supported prosthesis is presented here from our archive:}

\section{Case report 1}
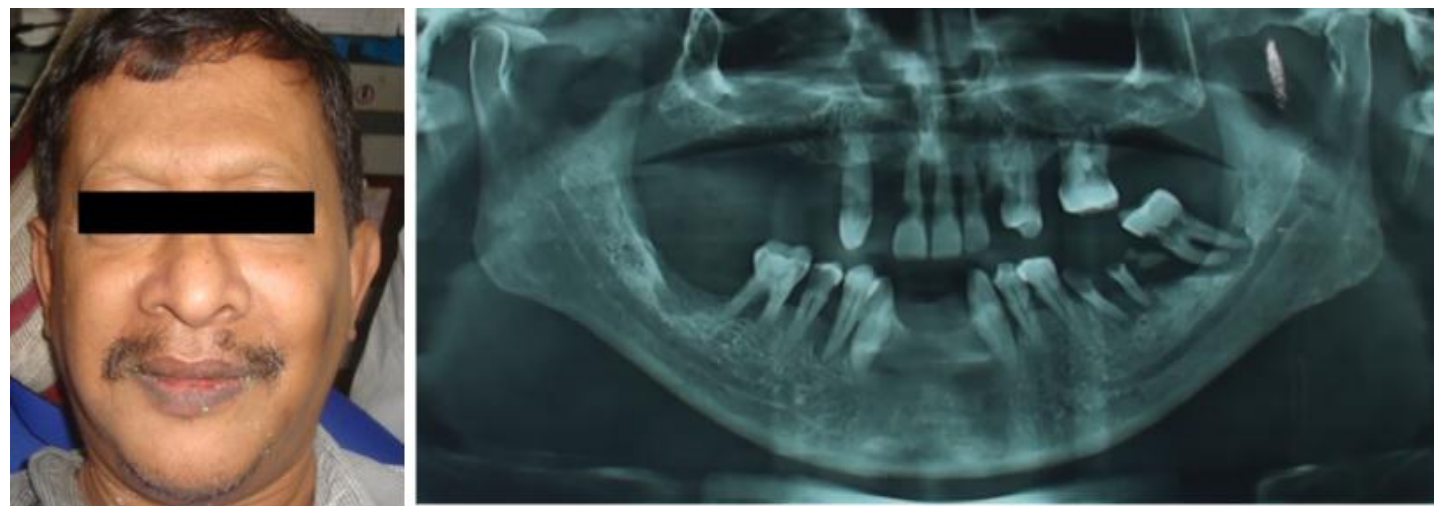

Pre -operative:
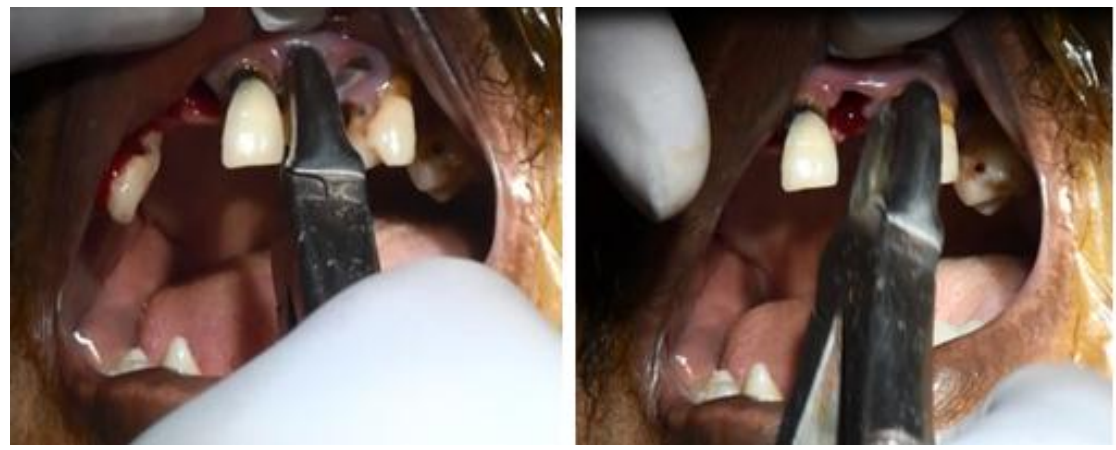

Extraction of grossly carious 21,22

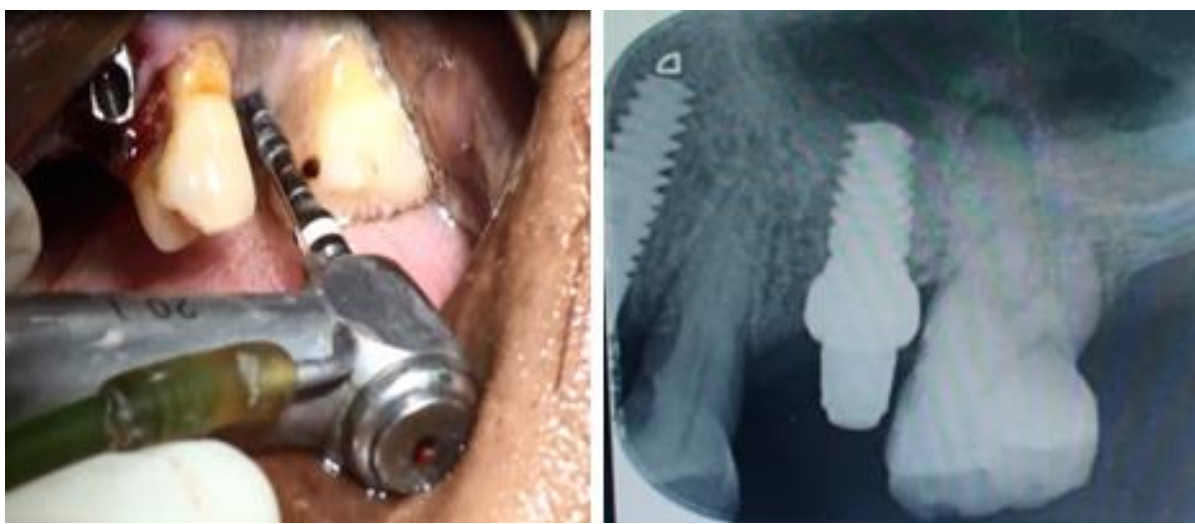

Implant placement in $21,23,25$

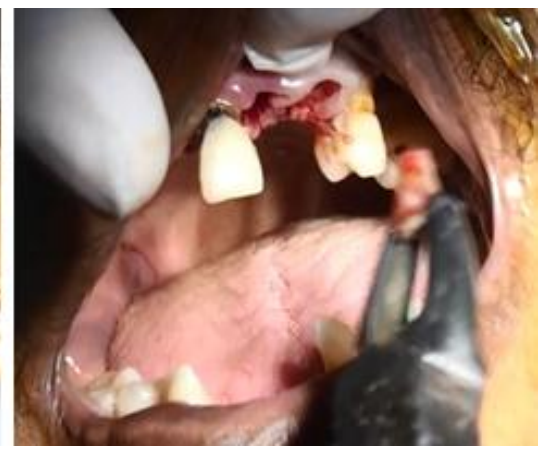



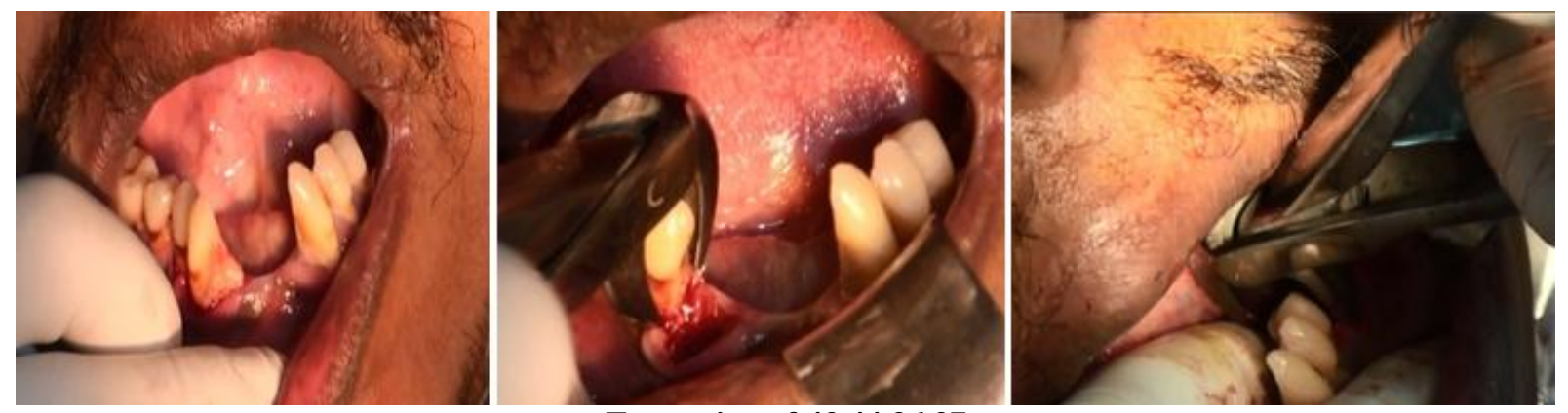

Extraction of 43,44,36,37
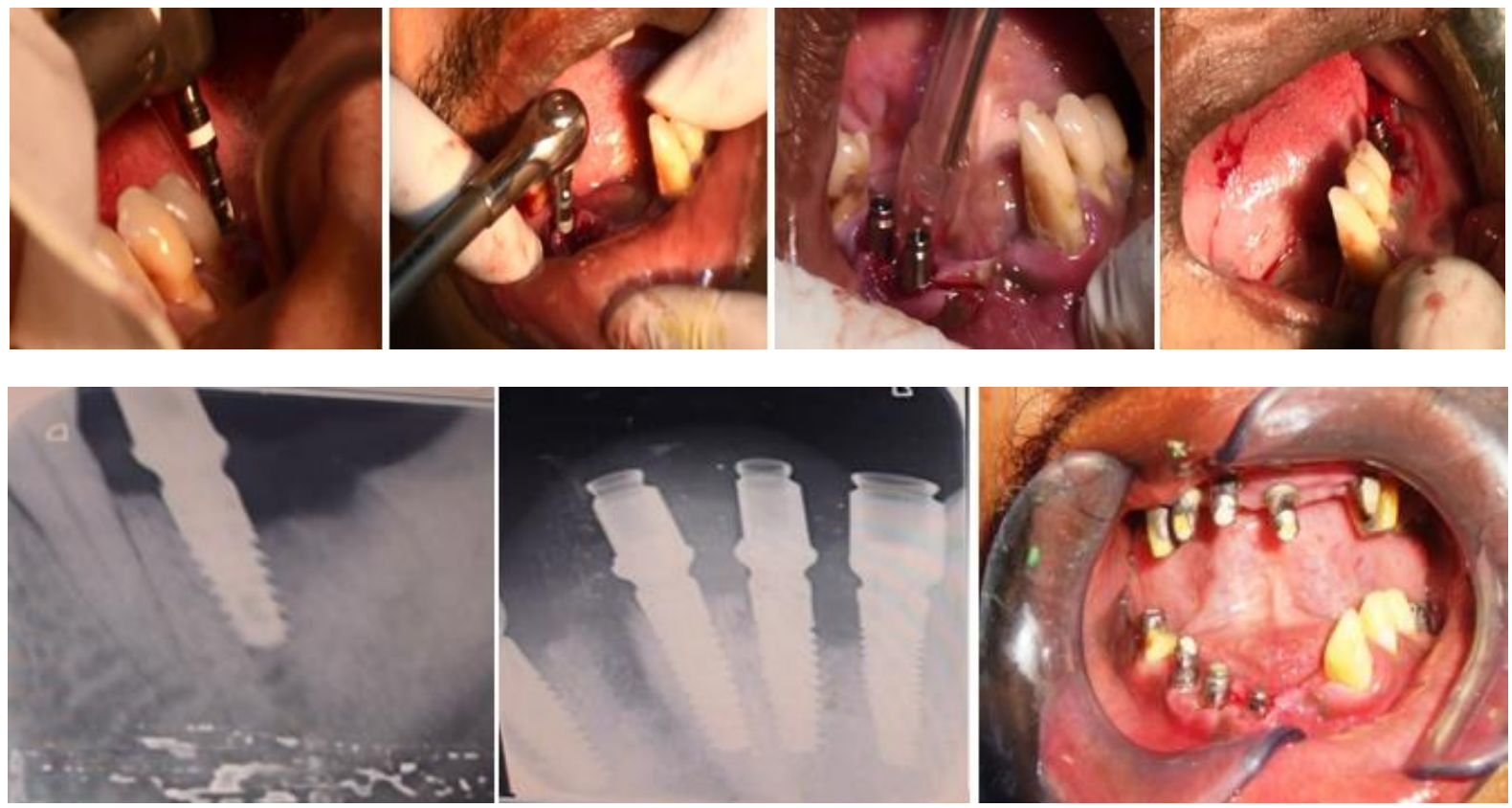

Implant placement in $36,37,43,44$
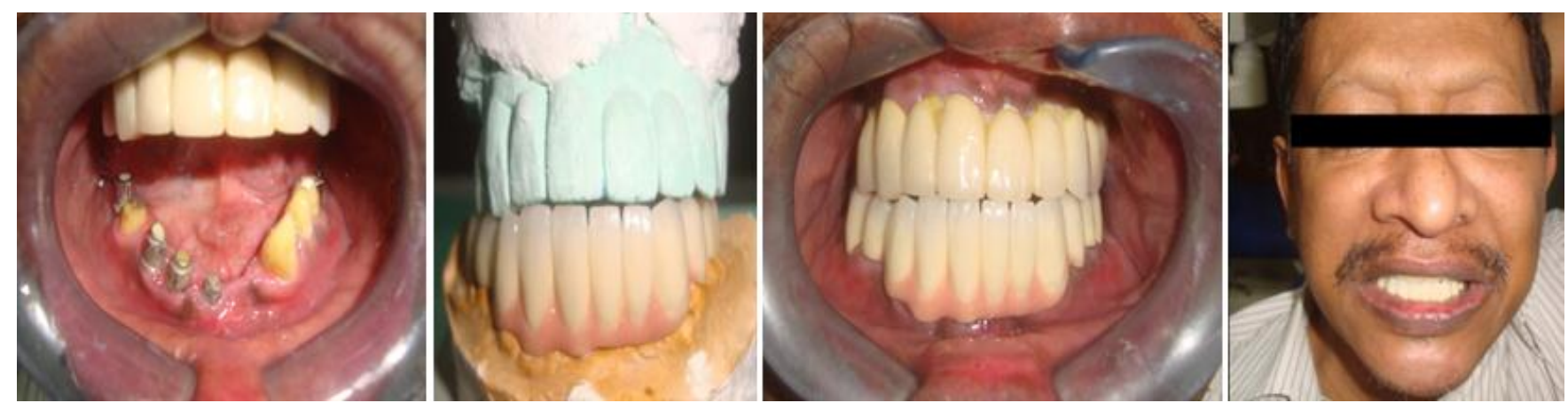

Prosthetic phase completed: 


\section{Case 2}

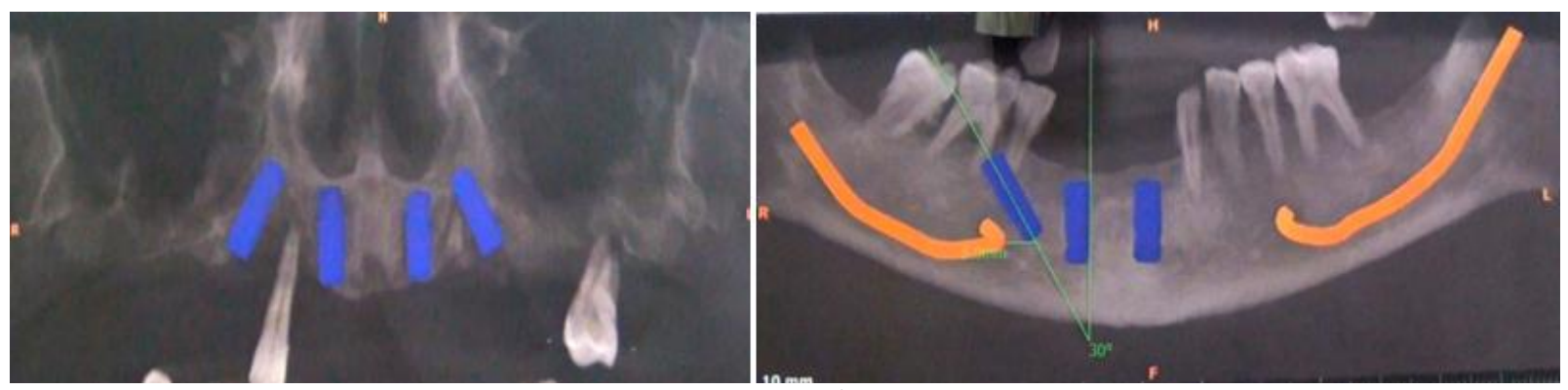

Pre-operative:

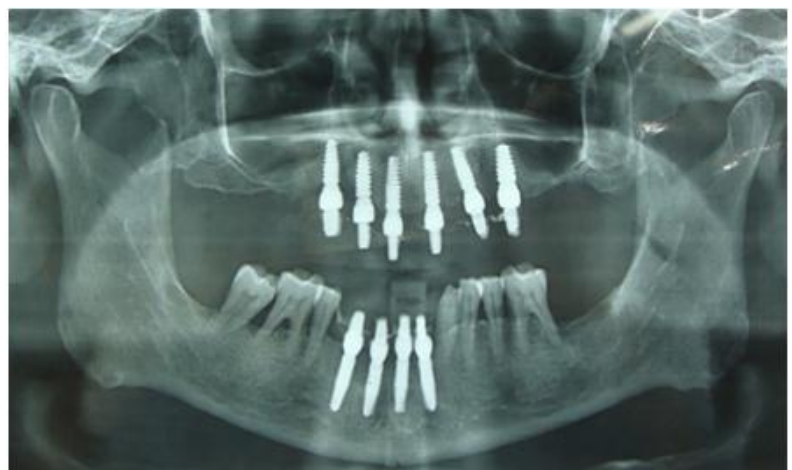

Implant placement:
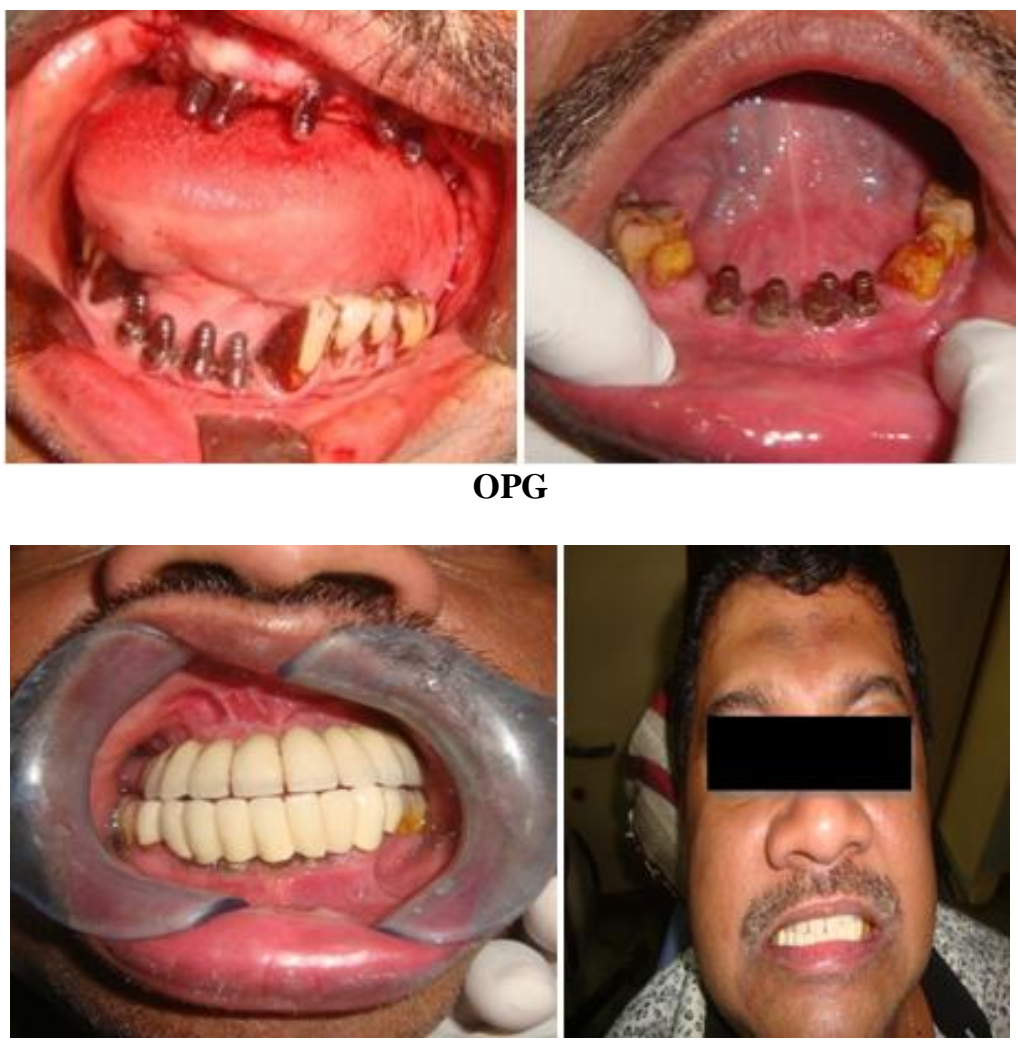

Post -operative: 


\section{Case 3}

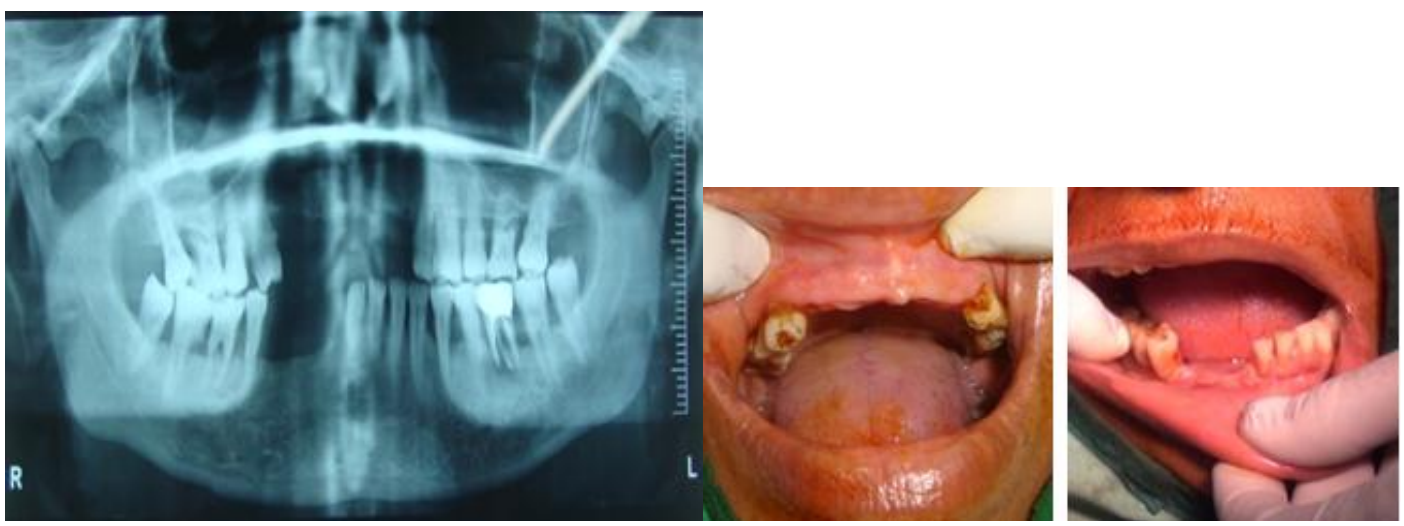

Pre-operative:
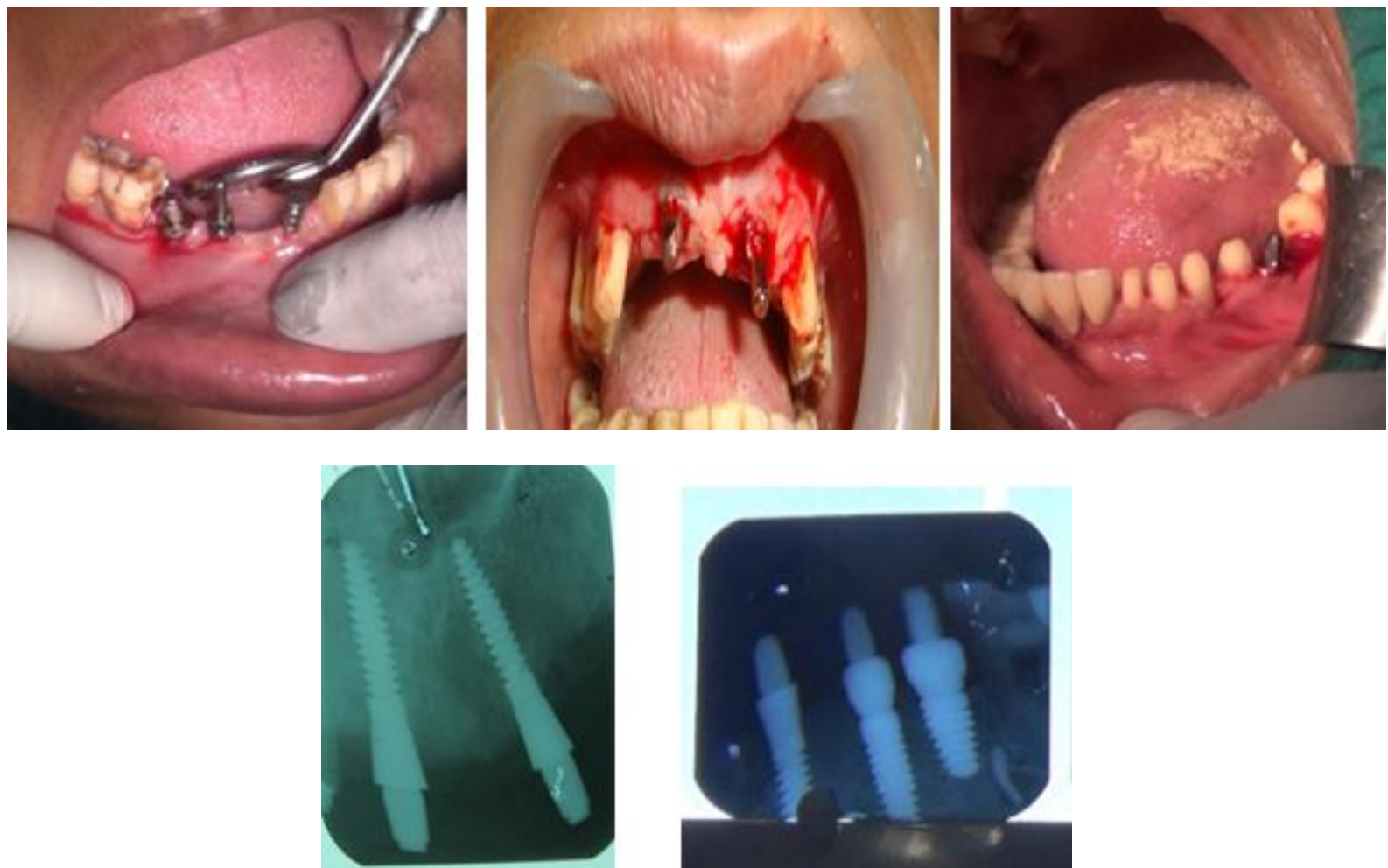

Implant placement
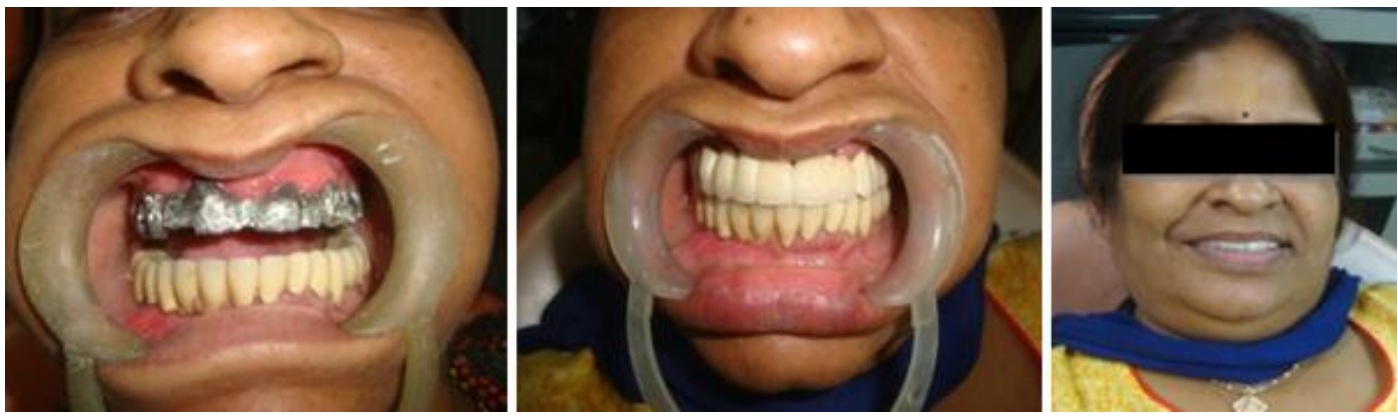

Prosthetic phase: 
Case 4
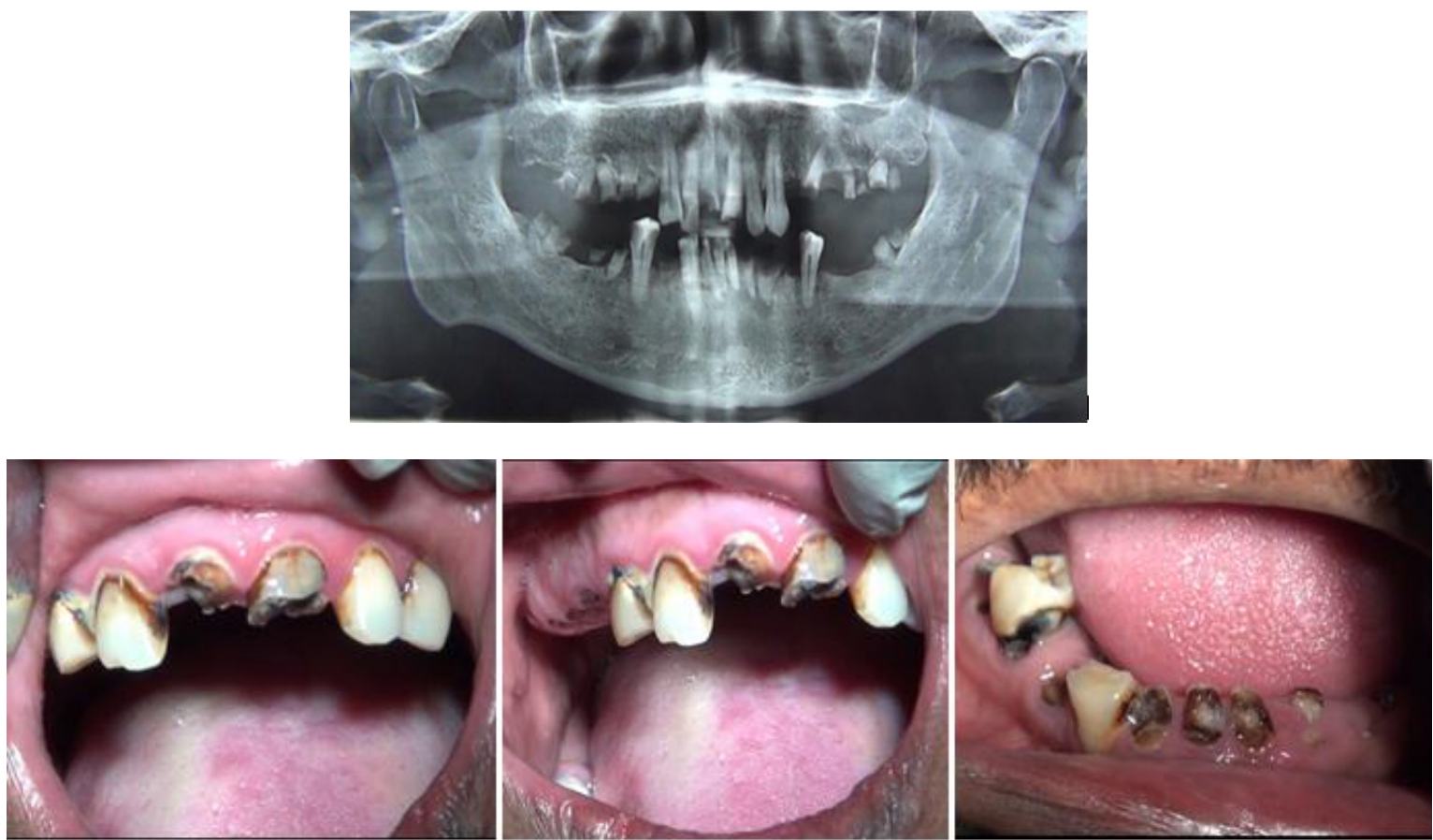

Preoperative:
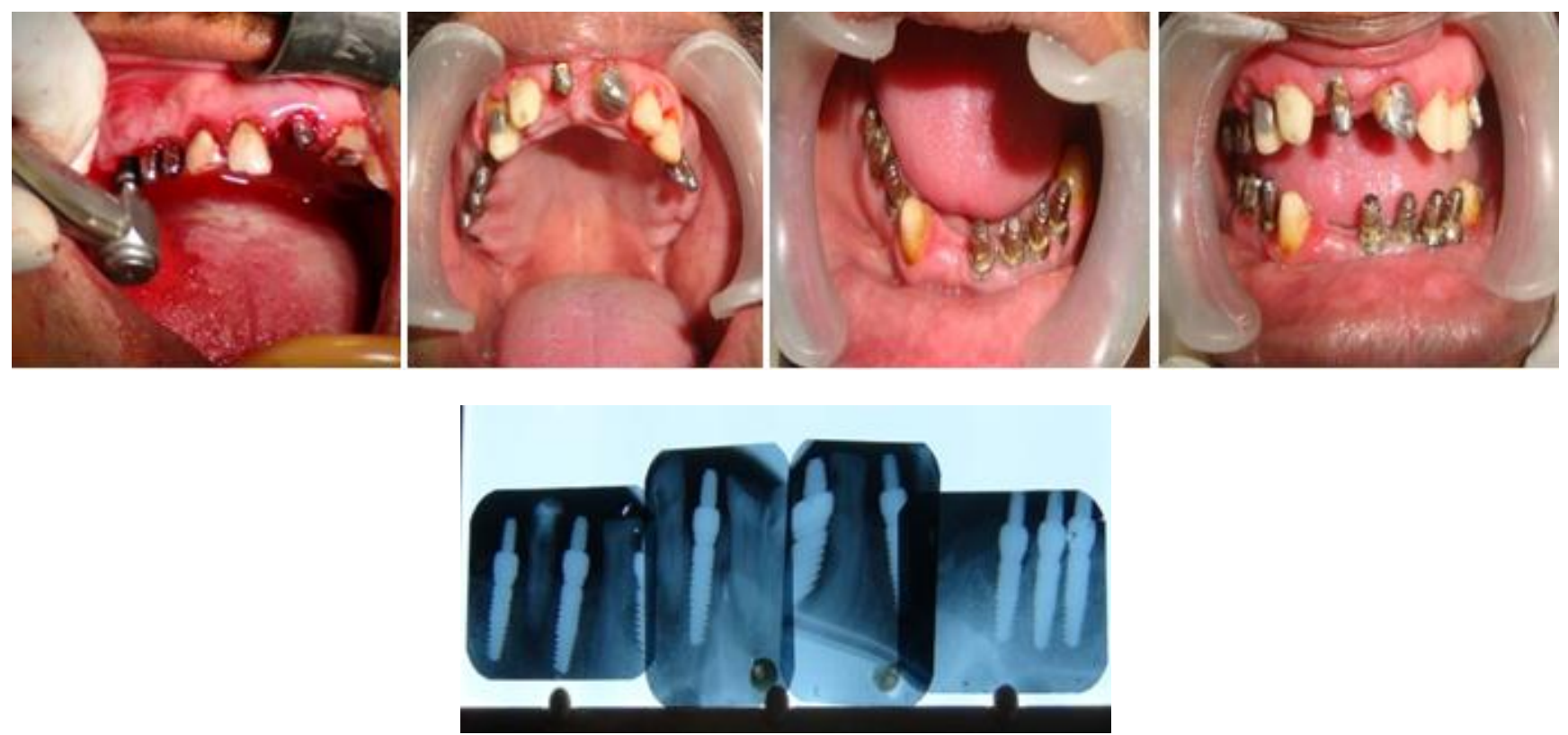

Implant Placement:
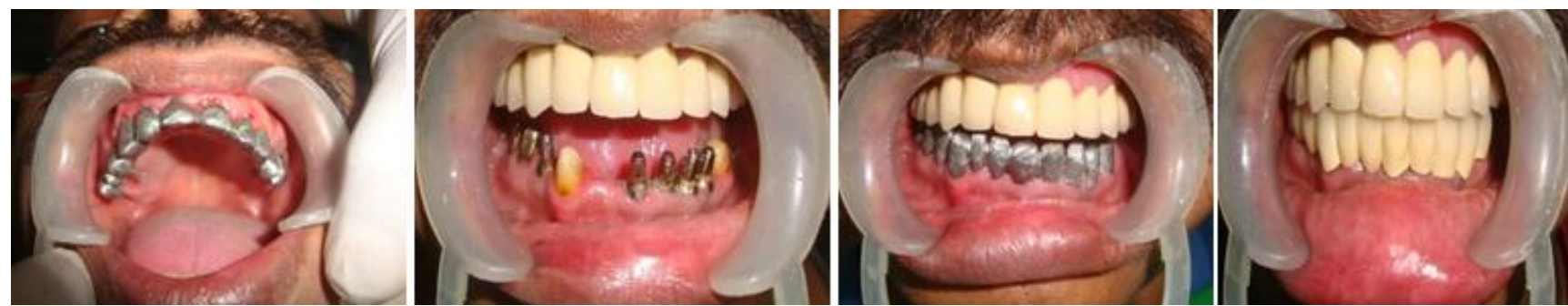

Prosthetic phase: 


\section{Case 5}
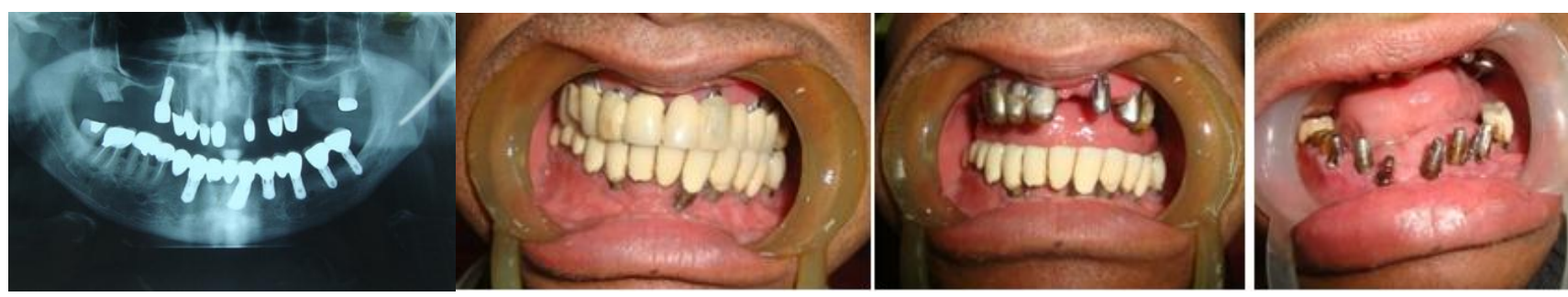

Pre-operative

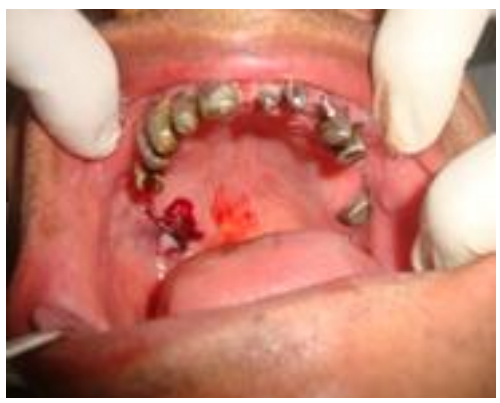

Extraction of 18
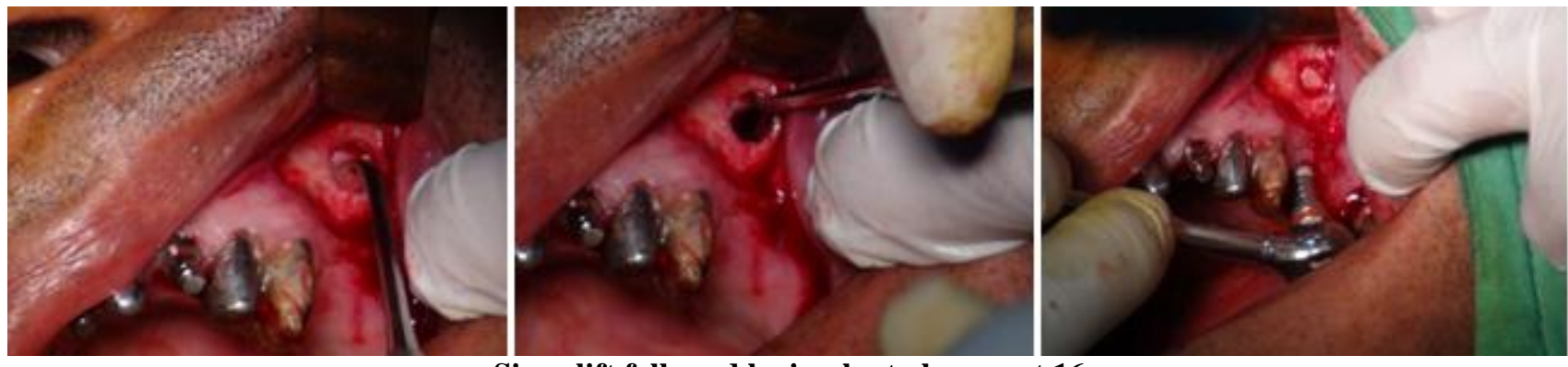

Sinus lift followed by implant placement 16

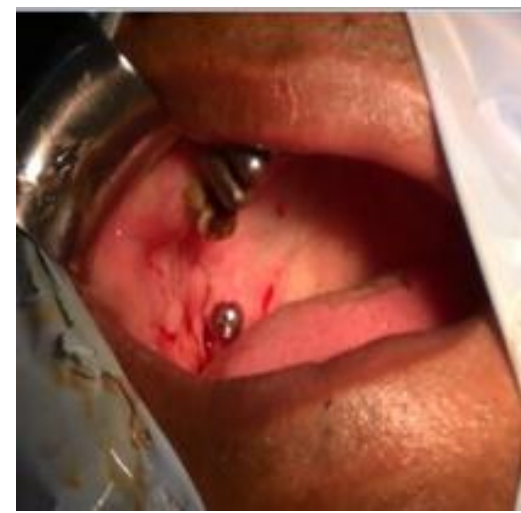

Implant placement in 17
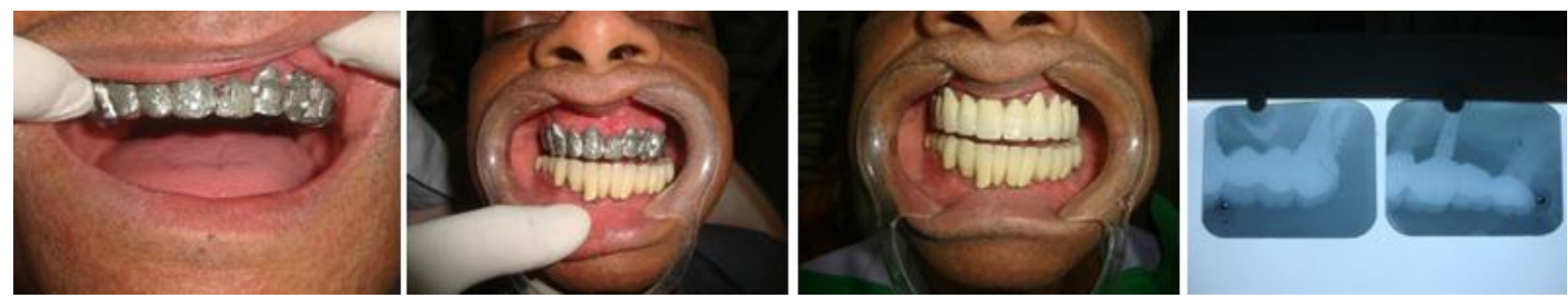
Case 6

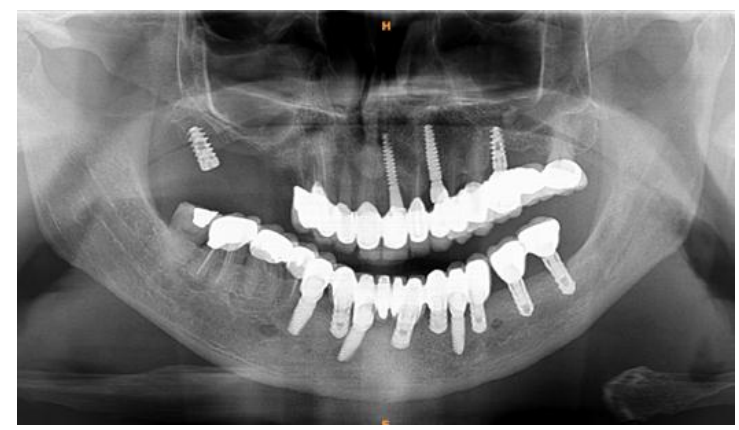

Prosthetic phase:

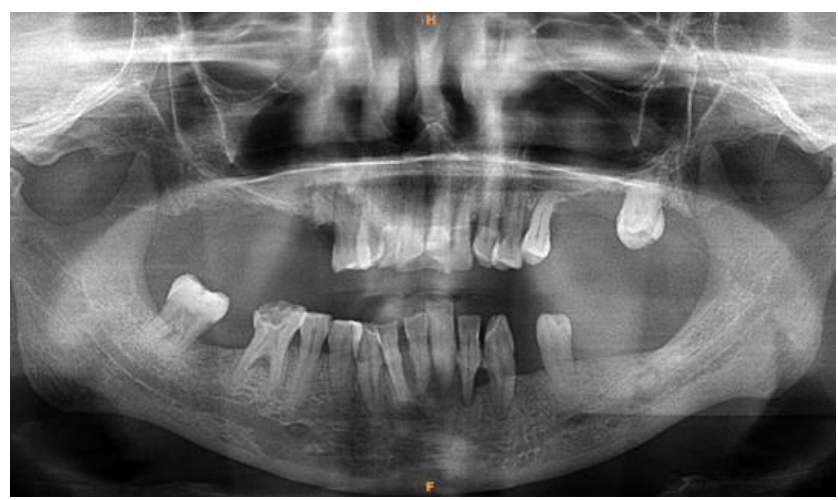

Pre-operative OPG

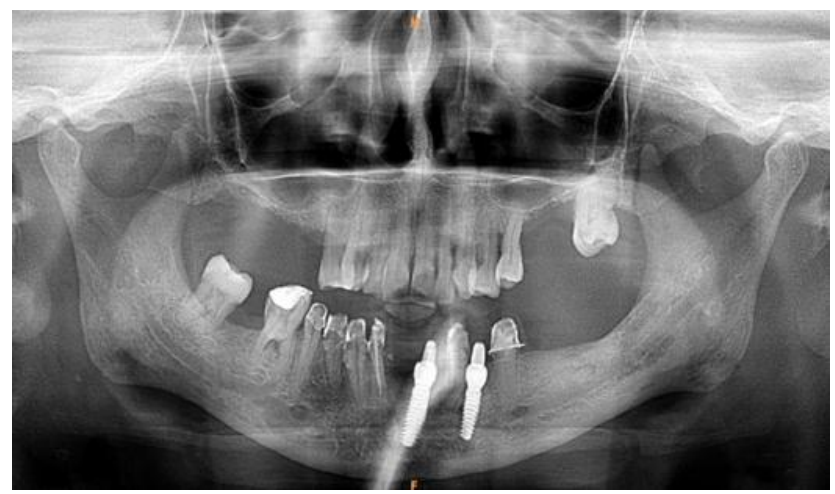

Post implant placement OPG
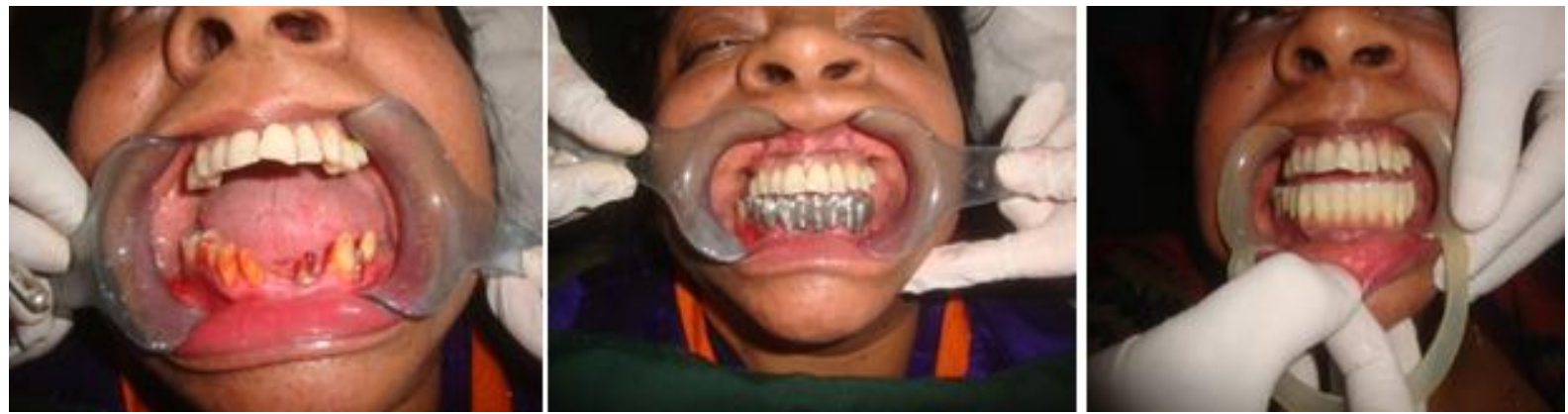

Prosthetic phase 


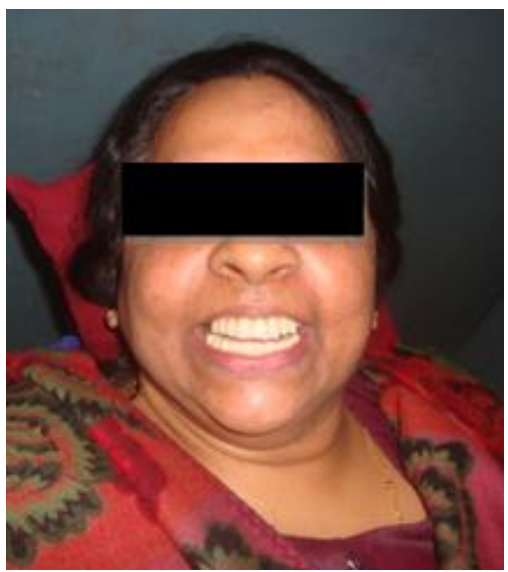

Post-operative:

\section{Case 7}

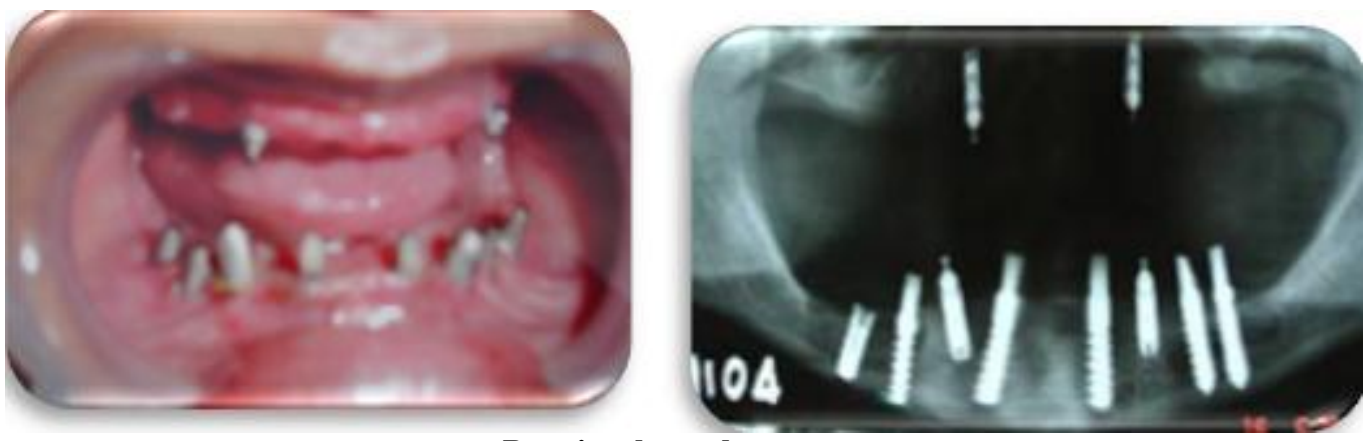

Post-implant placement:

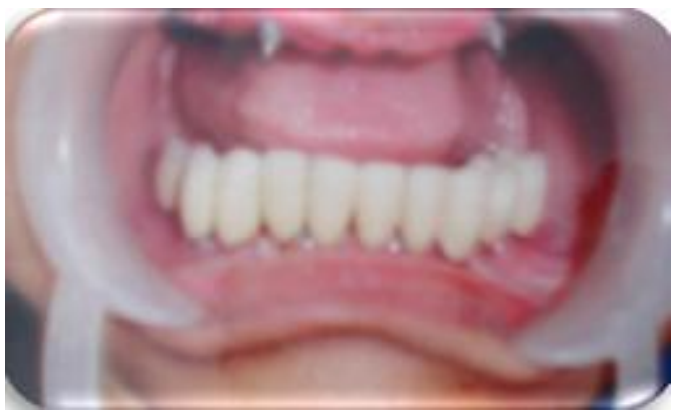

Prosthetic phase:

\section{Conflict of Interest: None.}

\section{References}

1. Rangart B Gunna J, Sullivan DY; Mechanical aspect of Branemark implant connected to a natural tooth: Int $J$ Maxillofac Implants 1991;6(2):177-186.

2. Rangart B: Biomechanics of Branemark system; Aust $J$ Prosthodont 1995-9:39-48

3. Cavvichia V, Bravi F: Free standing versus tooth connected implant supported fixed partial restorations: A comparative retrospective study of the prosthetic results

4. Vansteelberghee D: A retrospective multicentre evaluation of the survival rate ofossseointegrated fixtures supporting fixed partial prosthesis: J prosthet 1989;61(2);217-222.

5. Fugazzotto PA, Kirsch A, Ackermann KL. Implant/toothconnected restorations utilizing screw-fixed attachments: a survey of 3,096 sites in function for 3 to 14 years. Int J Oral MaxillofacImplants 1999;14(6):819-823.

6. Lindh T, Dahlgren S, Gunnarsson K. Tooth-implant supported fixed prostheses: a retrospective multicenter study. IntJ Prosthodont 2001;14(4):321-328.

7. Naert IE, Duyck JA, Hosny MM. Freestanding and toothimplant connected prostheses in the treatment of partiallyedentulous patients. Part I: an up to 15 -years clinical evaluation. Clin Oral Implants Res 2001;12(3):237244.

8. Nickenig HJ, Schäfer C, Spiekermann H. Survival and complication rates of combined tooth-implant-supported fixed partialdentures. Clin Oral Implants Res 2006;17(5):506-511.

9. Quirynen M, Naert I, van Steenberghe D, et al. Periodontal aspects of osseointegrated fixtures supporting a partial bridge. An up to 6-years retrospective study. J Clin Periodontol 1992; 19(2):118-126. 
10. Block MS, Lirette D, Gardiner D. Prospective evaluationof implants connected to teeth. Int J Oral Maxillofac Implants 2002;17(4):473-487.

11. Akça K, Uysal S, Cehreli MC. Implant-tooth-supported fixed partial prostheses: correlations between in vivo occlusal bite forces and marginal bone reactions. Clin Oral Implants Res 2006;17(3):331-336.

12. Brägger U, Karoussis I, Persson R. Technical and biological complications/failures with single crowns and fixed partial dentures on implants: a 10-year prospective cohort study. Clin Oral Implants Res 2005;16(3):326-334.

13. Fartash B, Arvidson K. Long-term evaluation of single crystal sapphire implants as abutments in fixed prosthodontics. Clin Oral Implants Res 1997;8(1):58-67.

14. Kindberg H, Gunne J, Kronström M. Tooth- and implantsupported prostheses: a retrospective clinical follow-up up to 8 years. Int J Prosthodont 2001;14(6):575-581.

15. Romeo E, Lops D, Margutti E. Long-term survival and success of oral implants in the treatment of full and partial arches: a 7-year prospective study with the ITI dental implant system. Int J Oral Maxillofac Implants. 2004;19(2):247-259.

16. 16.Greenstein G, Cavallaro J, Smith R, Tarnow D. Connecting teeth to implants: a critical review of the literature and presentation of practical guidelines. Compend Contin Educ Dent 2009;30:440- 453.

17. Odin G, Balaguer T, Savoldelli C, Scortecci G. Immediate functional loading of an implant-supported fixed prosthesis at the time of ablative surgery and mandibular reconstruction for squamous cell carcinoma. $J$ Oral Implantol 2010;36:225-230.

18. C.-L. Lin, S.-H. Chang, J.-C.Wang, andW.-J. Chang, "Mechanical interactions of an implant/tooth-supported system under different periodontal supports and number of splinted teeth with rigid and non-rigid connections," J Dent 2006:34(9):682-691.

19. Pesun IJ. Intrusion of teeth in the combination implant-tonatural- tooth fixed partial denture: A review of the theories. J Prosthodont 1997;6(4):268-277.

20. Ericsson I, Lekholm U, Brånemark PI, Lindhe J, Glantz PO, Nyman S. A clinical evaluation of fixed-bridge restorations supported by the combination of teeth and osseointegrated titanium implants. J Clin Periodontol 1986;13(4):307-312.

21. Schlumberger TL, Bowley JF, Maze GI. Intrusion phenomenon in combination tooth-implant restorations: A review of the literature. J Prosthet Dent 1998;80(2):199203.
22. C. E. English, "Root intrusion in tooth-implant combination cases," Implant Dentistry, vol. 2, no. 2, pp. 79-87, 1993.

23. C. G. Sheets and J. C. Earthman, "Tooth intrusion in implant assisted prostheses," J Prosthetic Dent. 1997;77(1):39-45.

24. C. E. RiederandS.M. Parel, "A survey of natural toothabutment intrusion with implant-connected fixed partial dentures," Int J Periodontics Restor Dent 1993;13(4):334-347.

25. M. S. Block, D. Lirette, D. Gardiner et al., "Prospective evaluation of implants connected to teeth," Int J Oral Maxillofac Implants 2002;17(4):473-487.

26. L. T. Garcia and L. J. Oesterle, "Natural tooth intrusion phenomenon with implants: a survey," Int J Oraland Maxillofac Implants 1998:13(2):227-231.

27. D. Y. Sullivan, "Prosthetic considerations for the utilization of osseointegrated fixtures in the partially edentulous arch," Int J Oral Maxillofac Implants 1986:1(1):39-45.

28. T. B. Ozc, elik and A. E. Ersoy, "An investigation of tooth/ implant-supported fixed prosthesis designs with two different stress analysis methods: an in vitro study," $J$ Prosthodont 2007;16(2):107-116.

29. A. Kirsch and K. L. Ackermann, "The IMZ osteointegrated implant system," Dent Clin North Am 1989;33(4):733-791.

30. A. Kirsch and P. J. Mentag, "The IMZ endosseous two phase implant system: a complete oral rehabilitation treatment concept," J Oral Implantol 1986:12(4):576- 589.

31. McGlumphy EA, Campagni WV, Peterson LJ. A comparison of the stress transfer characteristics of a dental implant with a rigid or a resilient internal element. $J$ Prosthet Dent 1989;62:586-593.

32. Mathews MF, Breeding LC, Dixon DL, Aquilino SA. The effect of connector design on cement retention in an implant and natural tooth-supported fixed partial denture. J Prosthet Dent 1991;65:822-287.

33. Nyman SR, Lang NP. Tooth mobility and the biological rationale for splinting teeth. J Periodontol 2000 1994;4:1522.

How to cite this article: Biswas BK, Das B, Saha A, Paul $\mathrm{R}$, Tooth implant supported prosthesis versus implant supported prosthesis- A review of literature and our experience. Indian $J$ Anat Surg Head Neck Brain 2018;5(1):1-12. 